\title{
ЛИНГВИСТИЧЕСКИЕ СРЕДСТВА МОДЕЛИРОВАНИЯ ДЕЯТЕЛЬНОСТИ ПРЕМЬЕР-МИНИСТРА ВЕЛИКОБРИТАНИИ БОРИСА ДЖОНСОНА В АНГЛОЯЗЫЧНЫХ И РОССИЙСКИХ СМИ
}

\section{LINGUISTIC MEANS FOR MODELING THE ACTIVITY OF BRITISH PRIME MINISTER BORIS JOHNSON IN THE ENGLISH AND RUSSIAN LANGUAGE MASS MEDIA}

\section{Kurbanov N. Golubnikov}

Summary: One of the most relevant issues in Linguistics and Media Discourse is the ways and means of forming the image of political figures. This article discusses all kinds of linguistic methods that further affect the consciousness of people. The research is based on internet-articles of Russian and foreign mass media. We will give it a try to describe the most popular linguistic tools at great length.

Keywords: discourse, media discourse, political image, mass media, metaphor.

\author{
Курбанов Ибрагим Алиевич \\ К.филол.н., професссор, БУВО «Сургутский \\ государственный университет» \\ Голубников Никита Игоревич \\ БУ ВО «Сургутский государственный университет» \\ golub.nick@yandex.ru
}

Аннотация: Одним из наиболее актуальных вопросов в лингвистике и медиадискурсе являются способы и средства формирования образа политических деятелей. В данной статье рассматриваются всевозможные лингвистические способы, которые в дальнейшем влияют на сознание широких масс. В качестве материала исследования служат интернет-статьи российских и зарубежных СМИ. Мы предпримем попытку подробного анализа наиболее популярных лингвистических средств.

Ключевые слова: дискурс, медиадискурс, политический образ, СМИ, метафора.
$\mathrm{B}$ наше время политика играет значительную роль в жизни человека, так как она затрагивает все сферы жизнедеятельности человека. В связи с этим появился интерес у лингвистов в изучении публичной, ораторской речи, а точнее к «политическому дискурсу».

Интересным является тот факт, что в научных кругах нет чёткого определения «политическому дискурсу», и по этой по этой причине, нам кажется важным в нашей работе выделить несколько понятий данного явления, характеризующих его как в узком, так и в широком смысле.

Лингвист В.3. Демьянков является приверженцем идеи, что политический дискурс следует рассматривать одновременно с трёх ракурсов: филологического, социопсихолингвистического и индивидуально-герменевтического, так как, по его мнению, политический дискурс в своей основе имеет междисциплинарный характер и его изучение неразрывно связано с анализом задач, формой и содержанием дискурса в политических ситуациях $[1$, с. 20].

К. Шаффнер поддерживает эту точку зрения, но при этом относит его к подкатегории дискурса, которому характерны функциональность и предметная направленность, а из этого можно сделать следующий вывод: политический дискурс как результат достижений в политической сфере, обусловлен культурно и исторически, как любой другой результат социальной деятельности людей, находящий отражение в языке [5, с. 36].

Третья группа учёных полагает, что язык политики обязателен к обособлению от других сфер речи. Е.И. Шейгал отмечает, что этот язык отличается «структурированной совокупностью знаков, образующих семиотическое пространство политического дискурса, в которое включаются специализированные знаки - как вербальные (политические термины, антропонимы), так и невербальные (политические символы), а также неспециализированные знаки, изначально номинативно не ориентированные на данную сферу общения, однако, вследствие устойчивого функционирования в ней, приобретающие содержательную специфику» [7, с. 114].

Мы можем отметить, что мнения ученых о задачах и функциях таких речевых актов сходятся.

К функциям относят - эффективность, оценочность, агрессивность (метафора, метонимия, гипербола, аллюзии и т.д.), риторические приёмы (ирония, инверсия, сарказм, восхваление и т.д.), фонетических особенностях.

Некоторые из этих особенностей даже позволяют отнести политический дискурс к художественному стилю речи. 
Лингвист Е.И. Шейгал первой привела классификацию речевых актов, в которых проявляется «язык политиков», руководствуясь положением единиц речи, характеристик выступающего и его отношений с реципиентом.

Также приводится группировка жанров по степени их официальности; отдельная группы присваивается руководителям государств.

Политическая лингвистика - это раздел языкознания, занимающийся изучением средств и приёмов, используемых в политических текстах разной направленности для достижения каких-либо целей. Данное направление сформировалось ещё в начале 20 века и активно начало включать в свой объект изучения метафоры в СМИ.

Согласно классификации Анатолия Прокопьевича Чудинова, политические метафоры можно классифицировать по следующим субсферам:

Антропоморфная метафора - моделирование человеком политической реальности исключительно по своему подобию. При исследовании этого разряда анализируются концепты, относящиеся к исходным понятийным сферам «Анатомия и физиология», «Болезнь», «Секс», «Семья».

Метафора природы - политические реалии осознаются в концептах мира окружающей человека природы. Источниками метафорической экспансии в данном случае служат понятийные сферы «Животный мир», «Мир растений». Традиционно различают живую природу (мир живых существ и растений) и природу неживую (ландшафт, стихии и др.), в своем исследовании А.П. Чудинов анализирует только метафоры живой природы и выделяет зооморфные (мир животных) и фитоморфные (мир растений) метафоры.

Социальная метафора - Исследуются концепты, относящиеся к понятийным сферам «Преступность», «Война», «Театр», «Игра и спорт».

Артефактная метафора - политические реалии представляются как предметы, созданные трудом человека. Автор рассматривает понятийные сферы «Дом (здание)» и «Механизм» [6, с. 55].

При анализе метафорического моделирования деятельности премьер-министра Британии Бориса Джонсона представляется целесообразным обратиться к методике, представленной в работе А.П. Чудинова. Согласно ей, описывая метафорическую модель, необходимо охарактеризовать её следующие признаки:

- исходную понятийную область (ментальную сферу-источник, сферу-донор), к которой относятся охватываемые моделью слова в первичном значении;

- новую понятийную область (ментальную сферумишень, денотативную зону), к которой относятся охватываемые моделью слова во вторичном значении; - относящиеся к данной модели фреймы, каждый из которых понимается как фрагмент наивной языковой картины мира и которые структурируют соответствующую понятийную область (концептуальную сферу);

- составляющие каждый фрейм типовые слоты, то есть элементы ситуации, которые включают какую-то часть фрейма, какой-то аспект его конкретизации, а также назвать типовые концепты, образующие слот;

- компонент, который связывает первичные и вторичные значения охватываемых данной моделью единиц, то есть выяснить, что дает основания для метафорического использования соответствующих слов;

- продуктивность и частотность метафорической модели, а также её «тяготение» к определенным функциональным стилям и подстилям, речевым жанрам, дискурсам и т.п., под продуктивностью в данном случае понимается возможность появления всё новых и новых вторичных значений, соответствующих модели;

- прагматический потенциал модели, то есть типовое воздействие соответствующих метафор на адресата [6, с. 122].

В процессе формирования общественного мнения в СМИ, важную роль в формировании имиджа политических деятелей играют разнообразные лингвистические средства. В мире, где отношения между странами зависят от личных качеств их лидеров, СМИ могут играть особую роль. Если журналист обратил внимание на какое-нибудь качество политика, даже неприметное, то он может просто пропустить его или обыграть таким образом, что это войдёт даже в историю [2, с. 32].

Аллюзия - это приём, позволяющий политическим деятелям продемонстрировать свою образованность, когда они ссылаются на литературные, исторические, мифологические и библейские факты.

Сравнение придаёт повествованию выразительность и привлекает внимание читателя к определенным свойствам предмета или субъекта.

Эпитеты в отличие от сравнения лишь передают, описывают определённые свойства субъекта как в положительном, так и в отрицательном смысле (коннотации).

При создании собирательного образа современного политического деятеля используются также речевые 
стандарты, клише, просторечные слова и выражения. Все это помогает сформировать обобщенный образ политика в массовом сознании государств и регионов. Невозможно дать однозначную оценку тем образам, которые западные и российские СМИ формируют по отношению к действующим политикам, поскольку отношение к ним, а соответственно и их образ, формируются в соответствии с экономической, политической, социальной и культурной обстановкой, как внутри страны, так и на международной арене [3, с. 74].

При рассмотрении образа Бориса Джонсона в британских СМИ наблюдается широкое использование такого тропа, как метафоры. Большое внимание в статьях уделяется политике выхода Великобритании из Евросоюза.

В статье газеты «The Guardian» от 3 марта 2020 года утверждается, что Борис Джонсон обещал стремительный выход из ЕС, но до сих пор решение этого вопроса затягивается:

«Boris Johnson's bluster on Brexit is about to face reality».

В словаре приводится следующее значение слова «bluster» - говорить по пустякам в грубом тоне. СМИ уверены, что пустые разговоры политика скоро столкнутся с не совсем приятной для Великобритании реальностью.

Как показывает анализ наиболее употребительных стилистических средств, многие относятся к Борису Джонсону пренебрежительно, что показано с помощью следующей метафоры с отрицательной коннотацией:

«Boris Johnson's intellect was hardly an instrument of surgical precision before it rubbed up against a hard Brexit». («The Guardian», 3 марта 2020).

Хотя само по себе выражение «instrument of surgical precision» имеет положительный смысл и переводится словосочетанием «инструмент хирургической точности», употребление с ним наречия «hardly» придает всей комбинации противоположный оттенок, и читателю становится ясно, что повествование ведется в критическом ключе.

Большую роль в политике Королевства также играют вопросы климата, и здесь Джонсон представлен с помощью метафор как мягкий политик, пытающийся самоутвердиться за счёт соглашений по климату:

"Johnson should claim the mantle of Margaret Thatcher... it is an opportunity for Johnson to show that he's broken with those dinosaurs of the past, and is instead showing that tackling climate change transcends tribal politics». («The Guardian», 03.03.2020)

Здесь мы можем заметить реализацию субсферы «Природа», сфера-источник - «неживая природа», фрейм
- климат. Значение «tackling climate change transcends tribal politics» не зафиксировано в словаре, так как это контекстуальная метафора, которая придумана автором статьи. Скорее всего она заимствована из области футбола или хоккея. Значение «tackle» в словаре определяется как «энергично браться за что-либо». Функциональная нагрузка метафоры заключается в том, что спортивная игра всегда проходит энергично и в примере показано, как импульсивно Борис Джонсон отстаивает вопросы климата, но при этом также рекомендует себя как прогрессивный политик, не ставя себя в сравнение с «динозаврами прошлого».

К тому же считается, что все неудачи в политике привели к потере уважения со стороны всей Британии, что показывается использованием метафоры с отрицательной коннотацией в газете «Independent» от 13 марта 2020 года.

"And I recognised that feeling of grief, and alienation, because in the last 18 months I have heard the same sentiments so often - from friends, from family, from people hailing me abusively in the street - as is their right.» (Brexit's speech)

Здесь мы также отмечаем использование субсферы «Природа», сфера-источник - «неживая природа», фрейм - «природные явления». Функциональная нагрузка метафоры заключается в том, что политика Бориса Джонсона была воспринята неоднозначно и на него словно «градом» была обрушена критика по поводу выхода из ЕС, неподдерживаемая многими британцами.

"There is surely no one who wishes anything other than for Johnson to succeed, but success and respect are not the same. In the case of the latter, that boat has long since sailed».

В качестве ещё одного примера можно привести выражение «six million points of light», когда упоминается о британской диаспоре, рассеянной по всему миру.

«We have a bigger diaspora than any other rich nation six million points of light scattered across an intermittently darkening globe».

Six million points of light - отметим метафору субсферы «Природа», сфера-источника «неживая природа»противопоставление света и тьмы, где шесть миллионов британских граждан, рассеянных по земному шару, изображаются как источники света на глобусе, периодически погружающемся во тьму.

Использование времени Present Perfect и маркера речи since показывает, что время упущено, «поезд ушел», и к Борису Джонсону уже не будет прежнего уважения, даже если его ждёт успех на политической арене.

Ещё одним важным тропом при создании образа Бориса Джонсона является эпитет. Так в газете «The Guardian» от 3 марта 2020 года показывается количество недо- 
вольных политикой Бориса Джонсона людей:

«Already, many of the prime minister's fiercest critics are now of the view that he must be afforded respect, for no reason beyond the enormity of the task he now faces».

Здесь мы также замечаем применение такого тропа, как гипербола. Значение слова «fierce» - свирепый усиливается с помощью использования формы превосходной степени, а также с помощью количественного квантификатора «many».

Способность к нелогичным действиям во время чрезвычайной ситуации, которой является пандемия коронавируса, также представляется через эпитеты.

"Johnson's cleverness is rhetorical; his unique talent is for lifting spirits while lowering expectations». («The Guardian», 03.03.2020)

Надежды Бориса Джонсона на то, что врачи всё также будут выполнять свою работу, а система здравоохранения будет работать безотказно, не оправдываются, а его уникальный талант теряет свою уникальность и не в силах совладать со сложной ситуацией, что в контексте передается противопоставлением словосочетаний «lifting spirits» и «lowering expectations».

При анализе текстов о Борисе Джонсоне нами также были обнаружены другие приёмы формирования образа, которые свойственны британскому медиадискурсу. Так было выявлено употребление окказионализма в следующем отрывке:

"That argument was the core of Frost's speech, which was Johnsonian in the way it camouflaged flabby thinking in historical dress». («The Guardian», 03.03.2020).

Использование окказионализма «Johnsonian» для выражения отношения к Борису Джонсону, а также употребление в составе метафоры эпитета «flabby», значение которого в словаре зафиксировано как дряблый, мягкий, бесформенный облекают смысл фразы отрицательной коннотацией. Таким образом, автор статьи как бы подчёркивает, что речи для премьер-министра пишутся кем-то, так как само мышление политика, а, следовательно, разумность принятия действий в политической жизни страны бедны и бесформенны.

Когда заходит речь о политике Бориса Джонсона по поводу выхода Великобритании из ЕС, в СМИ чаще встречаются отрицательные метафоры, которые помогают нам понять отношение к политике, проводимой премьером. Подтверждение этому можно найти в статье от 23 июля 2019 года в издании «ВВС. Русская служба»:

«Меня очень беспокоит, что его несет без руля и ветрил, все у него без плана, по наитию, на живую нитку».

Здесь мы можем отметить реализацию субсферы
«Артефакты», сферы-источника «Механизм», фрейм кораблестроение, слот - «части корабля». В плане функциональной нагрузки метафора представляет собой скрытое сравнение Бориса Джонсона с неуправляемым кораблем, что вызывает беспокойство и недоверие у его коллег по партии.

В следующем примере метафора с отрицательной коннотацией напрямую описывает стиль управления государством и принятия решений:

«Начинается темный лес, в котором надо на ощупь пробираться». («Радио Свобода», 23.07.2019)

В данной метафоре сферы-источника «Неживая природа», фрейм - «мир растений» отражается слот «лес». Под «тёмным лесом» подразумеваются все проблемы, оставленные после предыдущего премьера, а также проблемы политического раскола страны из-за Брексита, отказ Бориса Джонсона идти на компромисс по этому вопросу, что в итоге делает его символом этого раскола.

Эмотивность и оценочность суждения заложена и в эпитетах. Они тоже выражают субъективное мнение и формируют положительный и отрицательный образ, и имидж политиков.

Приведём пример позитивного отношения прессы к Борису Джонсону, его демонстрирует политический эксперт в статье издания «Радио Свобода» от 23 июля 2019 года:

«Он журналист очень сильный и блистательный оратор».

В статье идет речь об избрании Джонсона на пост премьер-министра и анализируются его положительные и отрицательные черты, которые он проявил не только на текущей должности, но и занимая другие посты. А так как Борис Джонсон пришёл в политику из журналистики, он явно хорошо владеет языком и пользуется своим особенным обаянием. Эти эпитеты несут в себе положительную коннотацию.

Однако далее в тексте той же статьи мы обнаруживаем совершенно противоположные выражения, которые явно указывают как будто на отрицательные характеристики персонажа.

«А тут - такой вроде поверхностный, порхающий Борис Джонсон, чуть ли не клоун, как его многие называют здесь». («Радио Свобода», 23.07.2019)

Но так как своё суждение высказывает один и тот же аналитик, негативное впечатление от нелестных на первый взгляд эпитетов сглаживается частицами «вроде» и «чуть ли», придающими прилагательным оттенок сомнения.

В статье издания «РИА новости», вышедшей 13 де- 
кабря 2019 года, можно найти следующую негативную оценку деятельности Джонсона:

«Жесткий Brexit Джонсона лишит британцев единого европейского рынка и нанесет удар по бизнесу, среднему классу и простым гражданам». («РИА новости», 13.12.2019).

Брексит - основная проблема последних нескольких лет для Великобритании, поэтому в текстах, где обсуждается выход из ЕС, используются красочные эпитеты. Учитывая контекст данного отрывка, мы видим, что негативная характеристика даётся не только действиям премьер-министра, но и ему самому. Эпитет «жёсткий» несет в себе эмотивный компонент упрямства, хотя ему бы следовало быть более гибким, так как его идеи отражаются не просто на политике партии, но и на будущем всего британского народа.

В статьях также присутствуют другие оценочные средства с положительной и отрицательной коннотацией. В процессе анализа статей, мы пришли к мнению, что большая часть примеров с положительной оценкой деятельности Бориса Джонсона относится к началу его вступления в должность, а на фоне предыдущего новый премьер воспринимается спасением для страны.

«...поклонники видят в нем едва ли не нового Черчилля...». («Радио Свобода», 23.07.2019).

В данном контексте перенос качеств легендарного политика на Бориса Джонсона подтверждает эту мысль, поднимает его статус и придает благородства образу политика. Образ Уинстона Черчилля соотносится с силой, волей, мудростью, процветанием государства, а аллюзия несет в себе положительный смысл.

При анализе текстов о Борисе Джонсоне нами были также выделены клишированные фразы, которые свойственны в большей степени российскому медиади- скурсу. Роль клише в политической речи заключается в том, чтобы дать краткую оценку, чтобы избежать ответа на неудобный вопрос или же для того, чтобы распространить речь «политической» лексикой и создать образ профессионала. Что касается употребления клише в текстах о политиках, то, вероятно журналисты используют такой язык для придания авторитетности своему мнению и тексту в целом, также причиной может послужить желание создать образ холодного и отрешённого политика. Нами были выделены следующие политические клише с положительной оценкой: «контакты налажены», «работать с полной отдачей», «оправдать доверие». Клише призваны придать речи нормированность, строгость; они также входят в основоопределяющие черты официально-делового стиля.

Все эти фразы находятся в разных статьях и не являются частью целостного образа, а, скорее, дополняют созданный другими лингвистическими средствами имидж. Вероятно, что такие клише, употребляются автоматически, непреднамеренно.

В статье «ВВС. Русская служба» от 23 июля 2019 года мы обнаруживаем также использование литоты с отрицательным значением, выражающего идею того, что Борис Джонсон не находит достаточной поддержки у своих однопартийцев.

«В оппозиции, во фракции лейбористов, есть сторонники «брексита» любой ченой, которые готовы поддержать Джонсона - но их меньше десятка, и эта гирька слишком мала, чтобы уравновесить мятежников-тори».

Подводя итоги, можно сделать вывод, что образ Бориса Джонсона не однозначен. Мы наблюдаем как положительные, так и отрицательные черты его репрезентации в СМИ. Последние как раз связаны с невыполнениями обещаний по поводу выхода Великобритании из Европейского союза.

\section{ЛИТЕРАТУРА}

1. Демьянков В.3. Политический дискурс как предмет политологической филологии. // Политическая наука. Политический дискурс: История и современные исследования. № 3. - М., 2002. - 120 с.

2. Михтинева И.М. Особенности перевода английских эмоционально-оценочных предложений на русский язык. / Автореф. дис. кан. фил. наук. М.: 1997. [Электронный ресурс]. - URL: http://cheloveknauka.com/osobennosti-perevoda-angliyskih-emotsionalno-otsenochnyh-predlozheniy-na-russkiyyazyk\#ixzz4g80Sp0Xm.

3. Паршин П.Б. Лингвистические методы в концептуальной реконструкции // Системные исследования, методологические проблемы. - М.: Наука, 1987. - 465 с.

4. Хомякова Н.А. Эмотивные фразеологизмы в русском, французском и английском языках (сопоставительный анализ). / Автореф. дис. кан. фил. наук.: $M, 2008 .-23 c$.

5. Ухачев Г.И., Куимова М.В. Некоторые особенности политической речи // Молодой учёный. - 2015. $\neg-$ №10. - 1047 с.

6. Чудинов А.П. Политическая лингвистика: Учеб.пособие / - Москва.: Наука. 2006. - 254 с.

7. Шейгал Е.И. Семиотика политического дискурса / ИТДГК «Гнозис», 2004. - 440 с.

( Курбанов Ибрагим Алиевич, Голубников Никита Игоревич (golub.nick@yandex.ru).

Журнал «Современная наука: актуальные проблемы теории и практики» 